\title{
How a Microorganism Corkscrews While It Breaststrokes
}

\author{
High-speed imaging and simulations show that the single-celled organism \\ called Chlamydomonas reinhardtii beats its flagella on separate planes, \\ explaining how it generates its helical movement.
}

\section{By Christopher Crockett}

W hen the single-celled Chlamydomonas reinhardtii does the breaststroke, it corkscrews through the water. Like U.S. Olympian Michael Phelps during the 200-meter final, the organism propels itself by synchronously whipping two tail-like appendages. But unlike Phelps, $C$. reinhardtii pivots around its long axis 1 to 2 times per second as it moves. Now, a pair of researchers have cracked the decades-old mystery of how these cells manage this movement: The tails of these creatures are genetically hardwired to whip slightly askew to one another [1].

Many single-celled organisms exhibit some sort of helical navigation. For $C$. reinhardtii, that ability is essential to its survival: The rotation allows the creature to scan its eye spot as it swims, like a radar dish sweeping the skies, and adjust course toward food or light.
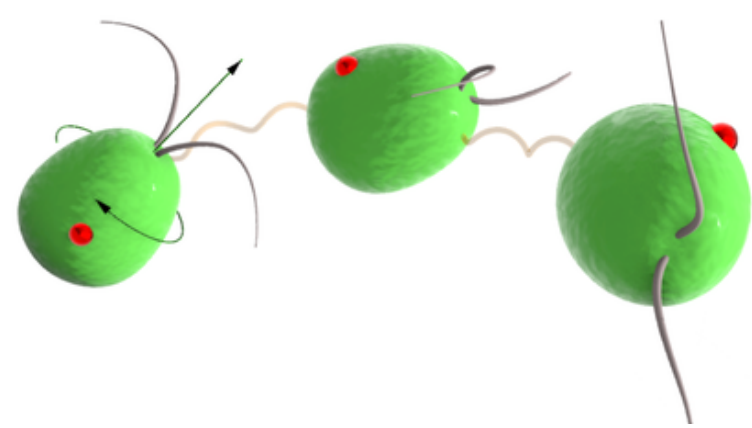

Credit: K. Y. Wan/University of Exeter

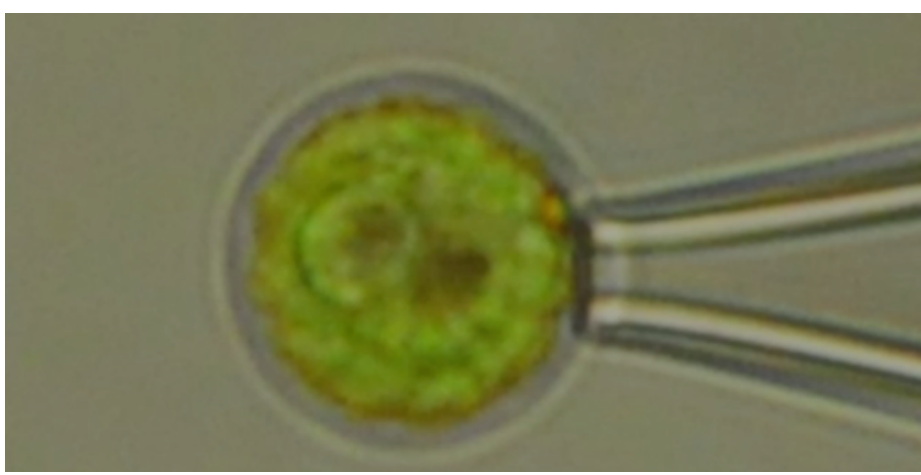

Video 1: High-speed video captures the beating of $C$. reinhardtii's two flagella. The process is viewed from above.

Credit: D. Cortese and K. Y. Yan [1]

To figure out what enables C. reinhardtii's swimming abilities, Dario Cortese and Kirsty Wan of the University of Exeter, UK, videoed individual organisms with high-speed cameras. The duo found that the appendages, or flagella, of $C$. reinhardtii beat on separate planes that are tilted with respect to one other. Creating a simple computer model of the observed behavior, they found that they could correctly predict its pattern and rate. The model also gave insight into how the cells turn left or right: they create a force asymmetry between the two flagella. Since helical movement is a general mechanism that microorganisms use to get around, the researchers say that these results could help in understanding how all manner of microscopic individuals navigate their world. 
Christopher Crockett is a freelance writer based in Arlington, Virginia.

\section{REFERENCES}

1. D. Cortese and K. Y. Wan, "Control of helical navigation by three-dimensional flagellar beating," Phys. Rev. Lett. 126, 088003 (2021). 